International Journal of Engineering \& Technology, $7(4.35)(2018) 932-938$
International Journal of Engineering \& Technology
SPC
Website: www.sciencepubco.com/index.php/IJET
Research paper

\title{
Low-load Efficiency Improvement of a Three-Phase Bidirec- tional Isolated DC-DC Converter (3P-BIDC) Via Enhanced Switching Strategy
}

\author{
N. S. Mohd Sharifuddin ${ }^{\mathrm{a}}$, N. M. L. Tan ${ }^{\mathrm{a}, \mathrm{b}}$, H. Akagic \\ ${ }^{a}$ Department of Electrical Power Engineering, Universiti Tenaga Nasional, Malaysia \\ ${ }^{b}$ Institute of Power Engineering, Universiti Tenaga Nasional, Malaysia \\ 'Department of Electrical and Electronic Engineering, Tokyo Institute of Technology, Japan \\ *Corresponding author E-mail: SE22704@utn.edu.my
}

\begin{abstract}
This paper presents the system design, operation and enhanced switching strategy of a three-phase bidirectional isolated dc-dc converter (3P-BIDC). The paper discusses the operating modes of the 3P-BIDC using phase-shift modulation (PSM), with analysis on its softswitching characteristics. The phase-shift modulation is the simplest modulation technique that can be applied to the 3P-BIDC. However, it comes with the consequences of low efficiency performance in the low-load conditions. Therefore, this paper investigates the improvement in efficiency of the 3P-BIDC during low-load condition using an enhanced switching strategy combining burst-mode switching and phase-shift modulation. The model of a 700-V, 100-kW, 20-kHz 3P-BIDC and the enhanced switching strategy are verified via simulation using PSCAD. The simulation results shows that the combination of burst-mode and phase-shift modulation technique improves the efficiency of the 3P-BIDC at low-load conditions.
\end{abstract}

Keywords: bidirectional isolated dc-dc converter; burst-mode switching; phase-shift modulation; ZVS; switching losses

\section{Introduction}

A bidirectional isolated dc-dc converter (BIDC) also known as the dual active bridge converter consists of two single-phase (1P) or three-phase (3P) full-bridge voltage-source converters that are galvanically isolated by a single- or three-phase high-frequency transformer. The BIDC plays a significant role in battery energy-storage systems for electric vehicles [1], grid-connected energy storage system [2], and more recently, solid-state transformers [3].

Publications have focused on the improvement in efficiency of 1PBIDC [4]-[5]. A new topology called the double stacked active bridge (DSAB) is proposed in [6] in order to extend the zero-voltage switching (ZVS) operating range. However, if applied to a three-phase topology, the system may have a more complex design and expensive cost due to the increased number of components.

Figure 1 shows the block diagram of the 3P-BIDC. The two DClink capacitors can handle high switching current ripples and maintain a nearly constant DC bus voltage. The three-phase bidirectional isolated dc-dc converter (3P-BIDC) has been less popular as compared to the single-phase topology because of a challenge in the practical realization of the three-phase high-frequency transformer with uniform leakage inductance. However, a 3P-BIDC is more attractive for high power density intensive applications such as in the automotive applications [7], MVDC shipboard power systems [8], LVDC power systems [9] and railway applications [10]. The 3PBIDC performs better than the single- phase BIDC when operated using the phase-shift modulation because the total input and output

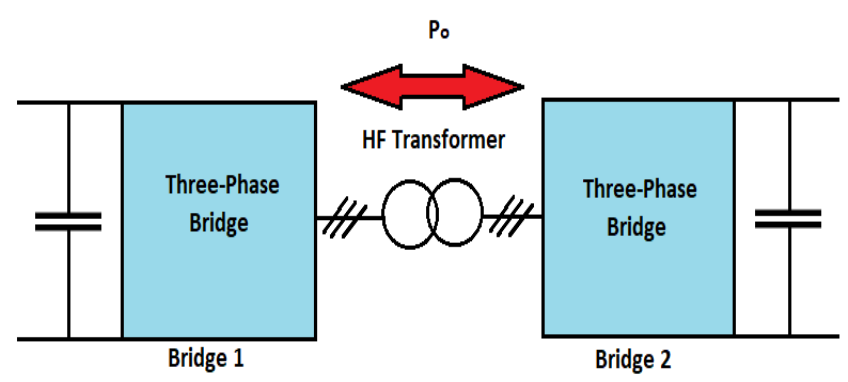

Fig. 1: 3P-BIDC block diagram.

filter requirements are lower [11]. The switching stress is distributed in the $3 \mathrm{P}-\mathrm{BIDC}$ to about $1 / 3$ of the switching stress in the $1 \mathrm{P}$ BIDC [12].

Phase-shift modulation (PSM) has been traditionally used to operate the 3P-BIDC. The technique is simple to understand and implement. The PSM can be simply controlled by adjusting the phaseshift angle $\delta$, which is the angle difference between the two AC phase voltages of bridges 1 and 2 in the 3P-BIDC. The optimum operation of the 3P-BIDC is when the ratio of the DC voltages is equal to its transformer turns ratio. However, when the ratio of the DC voltages are not equal to the transformer turns ratio, the region of high-efficiency is reduced [13]. Therefore, the overall high-efficiency of the 3P-BIDC cannot be maintained over a wide operating voltage and power range. 


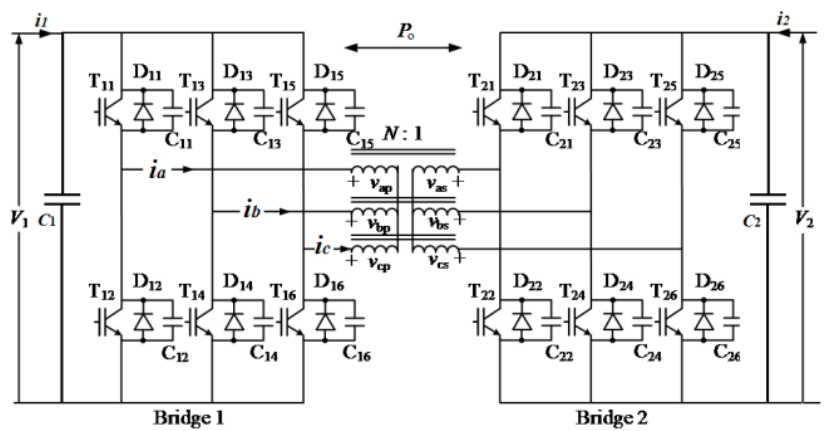

Fig. 2: A three-phase bidirectional isolated dc-dc converter.

Several other switching techniques have been introduced to improve the low-load efficiency of the 3P-BIDC using modulation techniques other than phase-shift modulation. The authors of [14] proposed triangular modulation technique that can increase the area of soft-switching to the low-load operations - from $16.67 \%$ of the rated power to the rated power. Moreover, trapezoidal and triangular modulation have been combined with phase-shift modulation to improve the overall efficiency of the converter [1]. However, triangular modulation is feasible only when the ratio of the DC voltages are not equal to the transformer turns ratio. On the other hand, the trapezoidal modulation causes high RMS currents in the BIDC Both switching strategies are also complex. Therefore, an enhanced switching strategy is required to maintain the overall efficiency of the three-phase BIDC across a wide operating power range.

A burst-mode switching (BMS) strategy has been verified to significantly improve the low-load efficiency of a 1P-BIDC [15]-[16] and also in other types of DC-DC converters [17]-[18]. In BMS, the transistors of the switching DC-DC converter are cyclically switched $\mathrm{ON}$ and $\mathrm{OFF}$ at a fixed frequency during a conducting period resulting in a burst of energy pulses transferred to the output, but they are permanently in the OFF-state during a non-conducting period [17].

This paper proposes the BMS for a 3P-BIDC. The BMS enables intermittent power transfer to the output during a low-load operation. Two switching strategies namely, the PSM and BMS can work together to provide a wider range of output power for the DC-DC converter to operate efficiently. This paper is arranged such that Sections 2 and 3 explains the 3P BIDC and the basic theory of the phase-shift modulation (PSM) strategy. Section 4 presents the simulation method combining the conventional PSM and the proposed BMS. Section 5 discusses results from the simulation and Section 6 is the conclusion.

\section{Three-Phase Bidirectional Isolated DC-DC Converter (3P-BIDC)}

Figure 2 shows the basic topology of the 3P-BIDC. It uses six IGBTs on each bridge. Power can be transferred from bridge 1 or bridge 2. The DC-link voltages of bridges 1 and 2 are $V_{1}$ and $V_{2}$, respectively. The semiconductor switches $T_{11}-T_{26}$ could be an

Table 1: Conducting components in the 3P-BIDC based-on positive-half cycle

\begin{tabular}{c|c|c}
\hline \hline Mode & Bridge 1 & Bridge 2 \\
\hline $\begin{array}{c}1 \\
\left(t_{0} \leq t<t_{1}\right)\end{array}$ & $\mathrm{T}_{12}, \mathrm{~T}_{14}, \mathrm{~T}_{15}$ & $\mathrm{D}_{22}, \mathrm{D}_{24}, \mathrm{D}_{25}$ \\
\hline $\begin{array}{c}\left.\text { (t } 1<t<t_{2}\right) \\
3\end{array}$ & $\begin{array}{c}\text { Soft-switching }\left(\mathrm{C}_{11}\right. \\
\left.\text { and } \mathrm{C}_{12}\right)\end{array}$ & $\mathrm{D}_{22}, \mathrm{D}_{24}, \mathrm{D}_{25}, \mathrm{~T}_{22}$ \\
\hline $\begin{array}{c}\left.t_{2} \leq t<t_{3}\right) \\
4\end{array}$ & $\mathrm{~T}_{11}, \mathrm{~T}_{14}, \mathrm{~T}_{15}, \mathrm{D}_{11}$ & $\begin{array}{c}\text { Soft-switching }\left(\mathrm{C}_{21}\right. \\
\left.\text { and } \mathrm{C}_{22}\right)\end{array}$ \\
\hline$\left(t_{3} \leq t<t_{4}\right)$ & $\mathrm{T}_{11}, \mathrm{~T}_{14}, \mathrm{~T}_{15}$ & $\mathrm{D}_{21}, \mathrm{D}_{24}, \mathrm{D}_{25}$ \\
\hline $\begin{array}{c}5 \\
\left(t_{4} \leq t<t_{5}\right)\end{array}$ & $\begin{array}{c}\text { Soft-switching }\left(\mathrm{C}_{15}\right. \\
\left.\text { and } \mathrm{C}_{16}\right)\end{array}$ & $\mathrm{D}_{21}, \mathrm{D}_{24}, \mathrm{D}_{25}, \mathrm{~T}_{25}$ \\
\hline
\end{tabular}

\begin{tabular}{|c|c|c|}
\hline $\begin{array}{c}6 \\
\left(t_{5} \leq t<t_{6}\right)\end{array}$ & $\mathrm{T}_{11}, \mathrm{~T}_{14}, \mathrm{~T}_{16}, \mathrm{D}_{16}$ & $\begin{array}{c}\text { Soft-switching }\left(\mathrm{C}_{25}\right. \\
\left.\text { and } \mathrm{C}_{26}\right)\end{array}$ \\
\hline $\begin{array}{c}7 \\
\left(t_{6} \leq t<t_{7}\right)\end{array}$ & $\mathrm{T}_{11}, \mathrm{~T}_{14}, \mathrm{~T}_{16}$ & $\mathrm{D}_{21}, \mathrm{D}_{24}, \mathrm{D}_{26}$ \\
\hline $\begin{array}{c}8 \\
\left(t_{7} \leq t<t_{8}\right)\end{array}$ & $\begin{array}{c}\text { Soft-switching }\left(\mathrm{C}_{13}\right. \\
\left.\text { and } \mathrm{C}_{14}\right)\end{array}$ & $\mathrm{D}_{21}, \mathrm{D}_{24}, \mathrm{D}_{26}, \mathrm{~T}_{24}$ \\
\hline $\begin{array}{c}9 \\
\left(t_{8} \leq t<t_{9}\right)\end{array}$ & $\mathrm{T}_{11}, \mathrm{~T}_{13}, \mathrm{~T}_{16,}, \mathrm{D}_{13}$ & $\begin{array}{l}\text { Soft-switching }\left(\mathrm{C}_{23}\right. \\
\left.\text { and } \mathrm{C}_{24}\right)\end{array}$ \\
\hline $\begin{array}{c}10 \\
\left(t_{9} \leq t<t_{10}\right)\end{array}$ & $\mathrm{T}_{11}, \mathrm{~T}_{13}, \mathrm{~T}_{16}$ & $\mathrm{D}_{21}, \mathrm{D}_{23}, \mathrm{D}_{26}$ \\
\hline $\begin{array}{c}11 \\
\left(t_{10} \leq t<t_{11}\right)\end{array}$ & $\begin{array}{l}\text { Soft-switching }\left(\mathrm{C}_{11}\right. \\
\left.\text { and } \mathrm{C}_{12}\right)\end{array}$ & $\mathrm{D}_{21}, \mathrm{D}_{23}, \mathrm{D}_{26}, \mathrm{~T}_{21}$ \\
\hline $\begin{array}{c}12 \\
\left(t_{11} \leq t<t_{12}\right)\end{array}$ & $\mathrm{T}_{12}, \mathrm{~T}_{13}, \mathrm{~T}_{16}, \mathrm{D}_{12}$ & $\begin{array}{l}\text { Soft-switching }\left(\mathrm{C}_{21}\right. \\
\left.\text { and } \mathrm{C}_{22}\right)\end{array}$ \\
\hline
\end{tabular}

2 are symmetrical and galvanically isolated by a high frequency three-phase transformer of turns ratio $N$. Compared to the 1P-BIDC, the 3P-BIDC topology may also provide the advantage of power distribution due to the increased number of switches available in the converter. The 3P-BIDC converter has higher power capability and lower ripple current on both input and output side, which leads to lower capacitor volume and higher power density [19]. The average power for the $3 \mathrm{P}-\mathrm{BIDC}$ when $0^{\circ} \leq \delta \leq 30^{\circ}$ is defined and analysed in [11], [20] and [21]:

$P_{o}=\frac{V_{1} N V_{2}}{2 \pi f_{s} L} \delta\left(\frac{2}{3}-\frac{\delta}{2 \pi}\right)$

Where $\delta$ is the phase-shift angle in radians of the AC phase voltages of bridges 1 and $2, f_{s}$ is the switching frequency, and $\mathrm{L}$ is the total leakage inductance at each phase referred to bridge 1 side.

\section{Operating Principles Based-on Phase-Shift Modulation}

In this section, the analysis of the 3P-BIDC operating waveforms are based-on soft-switching through the resonance between the snubber capacitor and transformer leakage inductances in each phase [12]. The authors of [21] assumed the commutations of current in the snubber capacitors to be instantaneous in the operating mode analysis. However, this section includes ZVS in the operating modes. In the 3P-BIDC, dead time is introduced as the duration when both switches in the same leg are in the off state to prevent short circuit to ground.

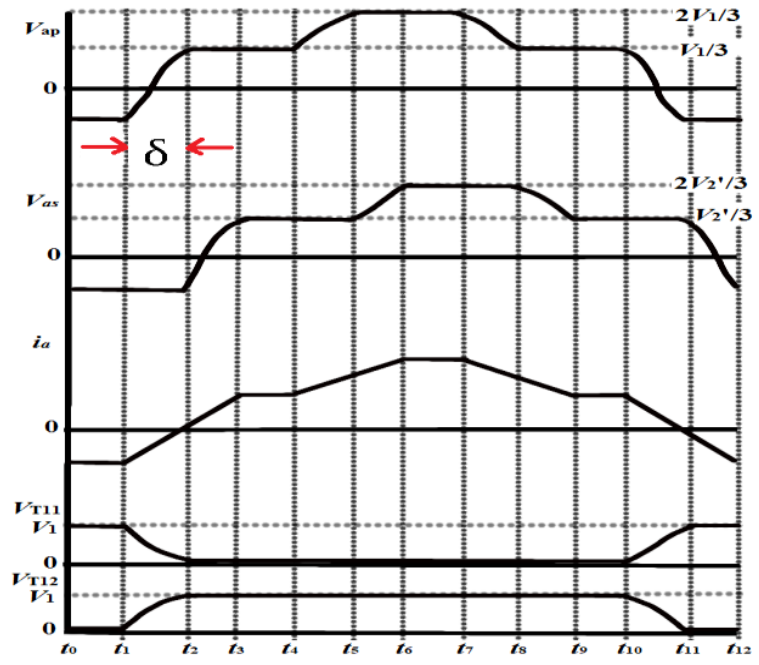

(a) 


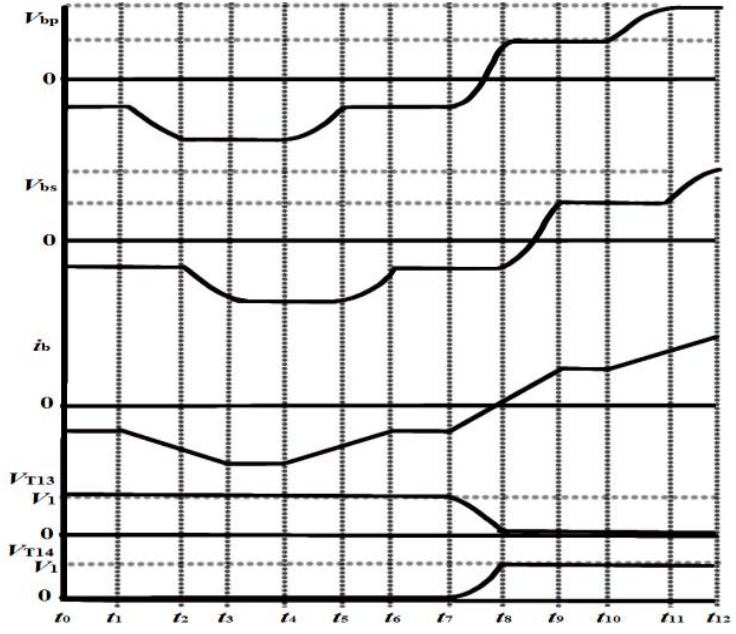

(b)

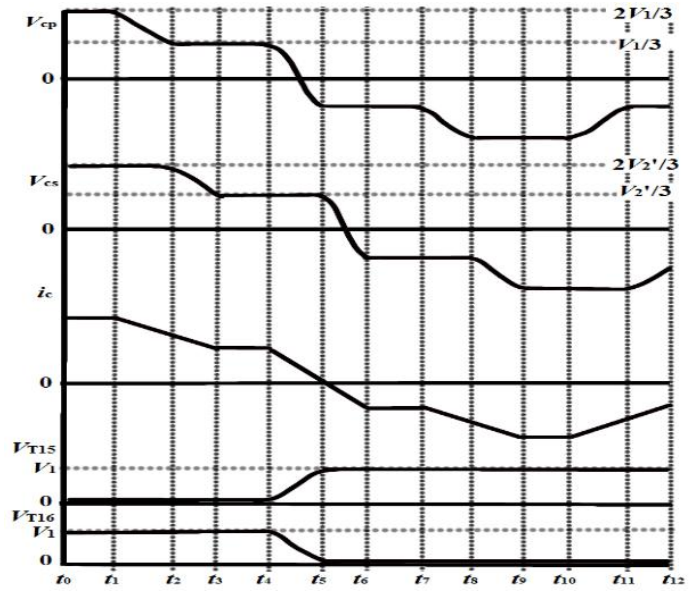

(c)

Fig. 3: Theoretical operating waveforms of the 3P-BIDC. (a) Phase A, (b) Phase B, and (c) Phase C.

The resonance between the snubber capacitors and the transformer leakage inductance takes place within the dead time of the semiconductor switches in the same leg [2], [17]. In this section, the dead time takes place from $t_{1}$ to $t_{2}$ in phase $\mathrm{A}, t_{7}-t_{8}$ in phase $\mathrm{B}$ and $t_{4}-t_{5}$ in phase $\mathrm{C}$.

During turn-off, the snubber capacitor is assumed to be large enough to minimize the rate of change of voltage across a semiconductor switch, almost achieving zero-voltage switching (ZVS) at turn-off. During turn-on, ZVS occurs when a gate signal is sent to the semiconductor switch as the converter current is clamped by its anti-parallel diode.

Table 1 shows the operating components of the 3P-BIDC in phase $\mathrm{A}$, phase $\mathrm{B}$ and phase $\mathrm{C}$ of bridge 1 that correspond to the main operating waveforms shown in Figures 3 (a), (b), and (c) respectively.

The operating modes of the 3P-BIDC consider ZVS operation. The voltages $V_{\text {ap }}$ and $V_{\text {as }}$ are the AC voltages of phase A in bridges 1 and 2 , respectively. Switches $\mathrm{T}_{11}, \mathrm{~T}_{12}, \mathrm{~T}_{21}$ and $\mathrm{T}_{22}$, their respective body diodes are $\mathrm{D}_{11}, \mathrm{D}_{12}, \mathrm{D}_{21}$, and $\mathrm{D}_{22}$ while the snubber capacitors are $\mathrm{C}_{11}, \mathrm{C}_{12}, \mathrm{C}_{21}$, and $\mathrm{C}_{22}$. The voltages across the snubber capacitors are

$V_{11}, V_{12}, V_{21}$ and $V_{22}$ respectively. The transformer leakage inductances in each phase is denoted by $L_{\mathrm{a}}, L_{\mathrm{b}}$, and $L_{\mathrm{c}}$. The time from $t_{1}$ to $t_{2}$ are the reference points for the phase-shift angle $\delta$.

Mode $1\left(\boldsymbol{t}_{\mathbf{0}} \leq \boldsymbol{t}<\boldsymbol{t}_{\mathbf{1}}\right)$ : From $t_{0}$ to $t_{1}$, the semiconductor switches $\mathrm{T}_{12}, \mathrm{~T}_{14}$ and $\mathrm{T}_{15}$ are conducting. $V_{\text {ap }}$ is equal to $-V_{1} / 3$. At time $t_{1}, \mathrm{~T}_{12}$ is gated-off marking the beginning of the dead time of phase $\mathrm{A}$ in mode 2 .

Mode $2\left(t_{1} \leq \boldsymbol{t}<\boldsymbol{t}_{2}\right)$ : The phase current, $i_{\mathrm{a}}$ is negative and flows through $\mathrm{T}_{12}$. Resonance starts to occur between the snubber capacitors $\mathrm{C}_{11}\left(\mathrm{C}_{12}\right)$, and $L_{\mathrm{a}} . \mathrm{C}_{11}$ discharges while $\mathrm{C}_{12}$ charges. $\mathrm{T}_{11}$ is gated on by ZVS.

Mode $3\left(\boldsymbol{t}_{2} \leq \boldsymbol{t}<\boldsymbol{t}_{3}\right)$ : At $t_{2}, V_{\text {ap }}$ is equal to $V_{1} / 3$. $V_{\mathrm{T} 11}$ attempts to overshoot to the negative rail and $\mathrm{D}_{11}$ is forward biased. After time $t_{2}$, Current $i_{\mathrm{a}}$ is positive and supplies energy to $V_{2}$.

Mode $4\left(\boldsymbol{t}_{3} \leq \boldsymbol{t}<\boldsymbol{t}_{4}\right)$ : From $t_{3}$ to $t_{4}$, the semiconductor switches $\mathrm{T}_{11}, \mathrm{~T}_{14}$, and $\mathrm{T}_{15}$ are conducting. $V_{\mathrm{cp}}$ is equal to $V_{1} / 3$. At the end of mode $4, \mathrm{~T}_{15}$ is gated to turn-off marking the beginning of the dead time of Phase $\mathrm{C}$ in mode 5.

Mode $5\left(\boldsymbol{t}_{\mathbf{4}} \leq \boldsymbol{t}<\boldsymbol{t}_{\mathbf{5}}\right)$ : The phase current $i_{\mathrm{c}}$ is positive and supplies energy to $V_{2}$. Resonance starts to occur between the snubber capacitors $\mathrm{C}_{15}\left(\mathrm{C}_{16}\right)$ and $\mathrm{L}_{c}$. $\mathrm{C}_{15}$ charges while $\mathrm{C}_{16}$ discharges. $\mathrm{T}_{16}$ is gated-on by ZVS.

Mode $6\left(\boldsymbol{t}_{\mathbf{5}} \leq \boldsymbol{t}<\boldsymbol{t}_{\mathbf{6}}\right)$ : At $t_{5}, V_{\mathrm{cp}}$ is equal to $-V_{1} / 3$. $V_{\mathrm{T} 16}$ attempts to overshoot to the negative rail and $\mathrm{D}_{16}$ is forward-biased. After time $t_{5}, i_{\mathrm{c}}$ is negative and flows through $\mathrm{T}_{16}$.

Mode $7\left(\boldsymbol{t}_{\mathbf{6}} \leq \boldsymbol{t}<\boldsymbol{t}_{\mathbf{7}}\right)$ : From $t_{6}$ to $t 7$, the semiconductor switches $\mathrm{T}_{11}, \mathrm{~T}_{14}$, and $\mathrm{T}_{16}$ are conducting. $V_{\mathrm{bp}}$ is equal to $-V_{1} / 3$. At the end of mode

7, $\mathrm{T}_{14}$ is gated to turn-off marking the beginning of the dead time of Phase $\mathrm{B}$ in mode 8 .

Table 2: 3P-BIDC circuit parameters

\begin{tabular}{c|c|c}
\hline \hline Parameters & Symbol & Values \\
\hline Rated Power & $P_{\mathrm{R}}$ & $100 \mathrm{~kW}$ \\
\hline Dc Voltage at bridge 1 & $V_{1}$ & $700 \mathrm{~V}$ \\
\hline Dc Voltage at bridge 2 & $V_{2}$ & $525 \mathrm{~V}-700 \mathrm{~V}$ \\
\hline Range of Phase-Shift Angle & $\delta$ & $-30 \leq \delta \leq 30^{\circ}$ \\
\hline Switching Frequency & $f_{\mathrm{s}}$ & $20 \mathrm{kHz}$ \\
\hline Dc-link Capacitors & $C_{1}, C_{2}$ & $10 \mathrm{mF}$ \\
\hline Snubber Capacitors & $C_{11}-C_{26}$ & $6 \mathrm{nF}$ \\
\hline Transformer Turns Ratio & $N: 1$ & $1: 1$ \\
\hline $\begin{array}{c}\text { Transformer Leakage Induct- } \\
\text { ances (each phase) }\end{array}$ & $L_{\mathrm{a}}, L_{\mathrm{b}}, L_{\mathrm{c}}$ & $11.91 \mu \mathrm{F}$ \\
& & \\
\hline
\end{tabular}

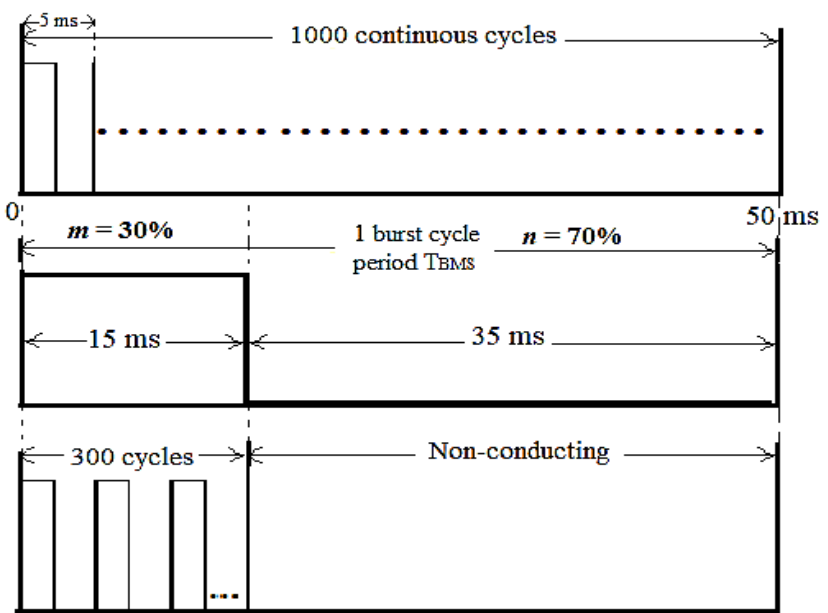

Fig. 4: Generation of BMS signals by multiplying $100020-\mathrm{kHz}$ with one $20-\mathrm{Hz}$ burst signal having a conduction period of $m=30 \%$.

Mode $8\left(\boldsymbol{t}_{\mathbf{7}} \leq \boldsymbol{t}<\boldsymbol{t}_{\mathbf{8}}\right)$ : The phase current $i_{\mathrm{b}}$ is negative and flows through $\mathrm{T}_{14}$. Resonance starts to occur between the snubber capacitors $\mathrm{C}_{13}\left(\mathrm{C}_{14}\right)$ and $\mathrm{Lb}_{b} \mathrm{C}_{13}$ discharges while $\mathrm{C}_{14}$ charges. From $t 7$ to $t_{8}, \mathrm{~T}_{13}$ is gated-on by ZVS. 
Mode $9\left(\boldsymbol{t}_{\mathbf{8}} \leq \boldsymbol{t}<\boldsymbol{t}_{\mathbf{9}}\right)$ : At $t_{8}, V_{\mathrm{bp}}$ is equal to $V_{1} / 3$. $V_{\mathrm{T} 13}$ attempts to overshoot to the negative rail and $\mathrm{D}_{13}$ is forward-biased. After $t_{8}, i_{\mathrm{b}}$ is positive and flows to $L_{b}$ via $T_{13}$.

Mode $10\left(\boldsymbol{t}_{\mathbf{9}} \leq \boldsymbol{t}<\boldsymbol{t}_{\mathbf{1 0}}\right)$ : From $t_{9}$ to $t_{10}$, the semiconductor switches $\mathrm{T}_{11}, \mathrm{~T}_{13}$ and $\mathrm{T}_{16}$ are conducting. $V_{\text {ap }}$ is equal to $V_{1} / 3$. At the end of mode $10, T_{11}$ is gated to turn-off marking the beginning of the dead time of phase $\mathrm{A}$ in mode 11.

Mode $11\left(\boldsymbol{t}_{10} \leq \boldsymbol{t}<\boldsymbol{t}_{11}\right)$ : The phase current $i_{\mathrm{a}}$ is positive and La supplies energy to $V_{2}$. Resonance starts to occur between the snubber capacitors $\mathrm{C}_{11}\left(\mathrm{C}_{12}\right)$ and $\mathrm{La}$. $\mathrm{C}_{11}$ charges while $\mathrm{C}_{12}$ discharges. From $t_{10}$ to $t_{11}, T_{12}$ is gated on by ZVS.

Mode $12\left(\boldsymbol{t}_{\mathbf{1 1}} \leq \boldsymbol{t}<\boldsymbol{t}_{\mathbf{1 2}}\right)$ : At $t_{11}, V_{a p}$ is equal to $-V_{1} / 3$. $V_{\mathrm{T} 12}$ attempts to overshoot to the negative rail and $\mathrm{D}_{12}$ is forward-biased. After time $t_{11}, i_{a}$ is negative and flows through $\mathrm{T}_{12}$.

Note that in a practical system, hard-switching and incomplete ZVS is likely to occur. Hard-switching operation may occur in the DCDC converter during light-load conditions whereas incomplete ZVS

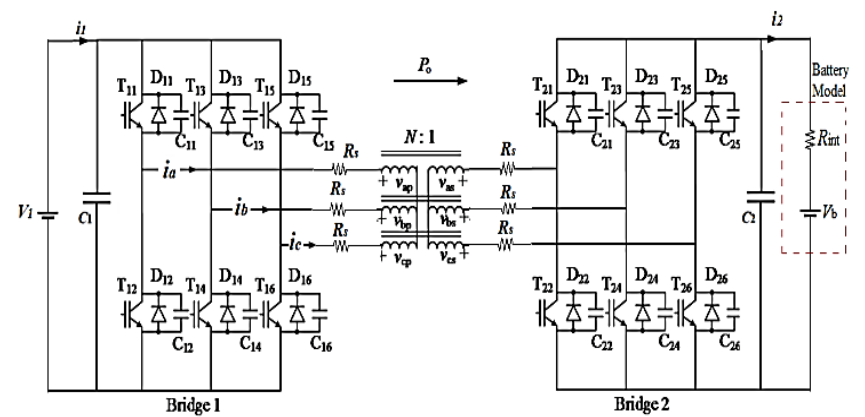

Fig. 5: The simulation model

occurs when the snubber capacitors of one leg in a bridge does not completely discharge to zero voltage, when a semiconductor switch is turned on.

\section{Simulation Model and Proposed Enhanced Switching Strategy}

The proposed strategy combines two switching techniques. In the medium to high power transfer region, $20 \%$ of rated power to the rated power, only phase-shift modulation is employed. In the low power transfer region, less than $20 \%$ of the rated power, the combination of BMS and PSM is employed. The simulation model verification is carried out using PSCAD software. Moreover, efficiency measurement is also carried out in the simulation.

The converter efficiency is calculated as the ratio of the DC output power in equation (3) to the DC input power in equation (2) when power is transferred from bridge 1 to bridge 2 .

$P_{\mathrm{i}, \mathrm{DC}}=V_{1} I_{1}$

$P_{\mathrm{o}, \mathrm{DC}}=V_{2} I_{2}$

Table 2 presents the circuit parameters of the 3P-BIDC shown in Figure 2. The rated power and voltage of the converter is $100 \mathrm{~kW}$ and $700 \mathrm{~V}$ respectively. The transformer leakage inductances in each

phase is designed based on equation (1). In this paper, a positive phase-shift angle, $\delta$ is assumed when power is transferred from bridge 1 to bridge 2 .

Figure 4 describes the theory of generating burst-mode switching (BMS) that enables intermittent power transfer during low-load operation. 300 cycles of burst mode signals with a duty cycle of $30 \%$ are generated via the multiplication of two input signals. The BMS is obtained from the generation of 300 cycles of $20-\mathrm{kHz}$ signals with a duty cycle of $50 \%$ multiplied with one $20-\mathrm{Hz}$ conduction signal having a period of $m=30 \%$. The BMS in bridge 2 are generated in the same manner. Note that " $m$ " is the conducting period in percentage of the burst mode signal and " $n$ " denotes the nonconducting period in percentage. In the case demonstrated here, " $m$ " is $30 \%$ and " $n$ " is $70 \%$. The burst mode switching strategy are simulated and compared with only PSM strategy in low-load conditions. When the conducting period of the BMS is set to $10 \%, m=10 \%$ and $n=90 \%$. The sum of " $m$ " and " $n$ " should always be $100 \%$.

For low-power operation, BMS is combined with PSM as the enhanced switching strategy. Therefore, the control of the phase-shift angle $\delta$ is also required, in addition to the control of $m$ and frequency value of the low-frequency signal.

$f_{\mathrm{BMS}}=1 / \mathrm{T}_{\mathrm{BMS}}$

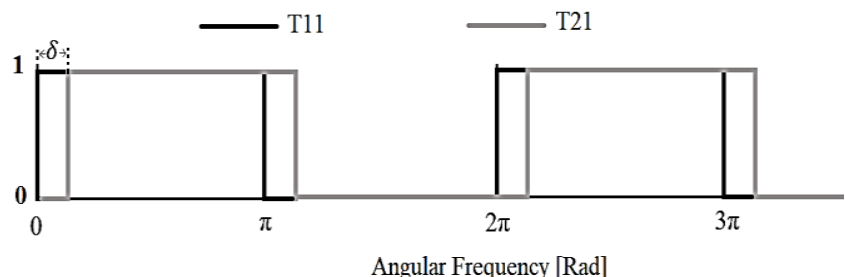

Fig. 6: Gate signals to switches $T_{11}$ and $T_{21}$ at $\delta=30^{\circ}$ using phase-shift modulation.

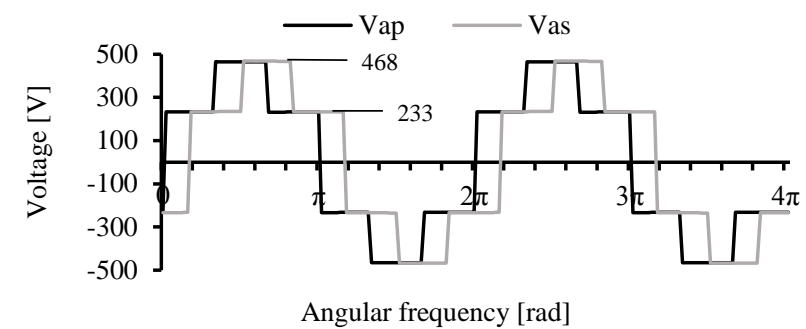

Fig. 7: AC voltages at bridges 1 and 2 using phase-shift modulation at $V_{1}=$ $V_{2}=700 \mathrm{~V}, \delta=30^{\circ}$.
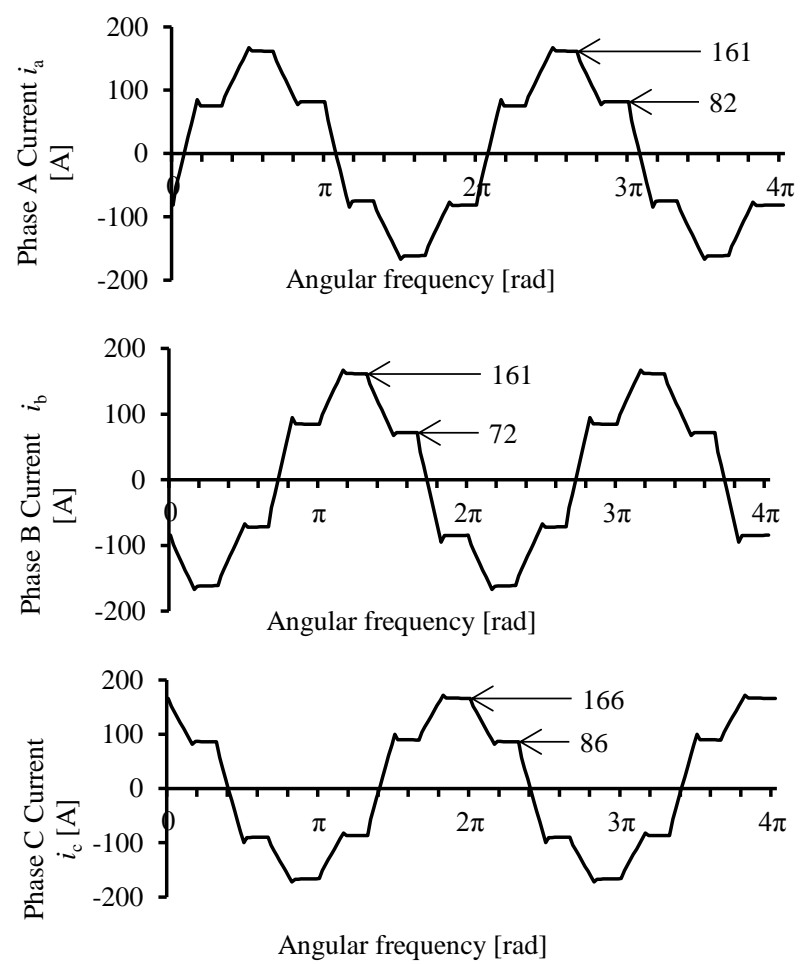

Fig. 8: Inductor current waveforms. 
Figure 5 presents the simulation model that is used to verify the proposed enhanced switching strategy. The model is applied for battery charging and discharging. A battery model is connected in the output terminal with a voltage, $V_{\mathrm{b}}$ of $525 \mathrm{~V}$ to $700 \mathrm{~V}$ and an internal resistance, $R_{\text {int }}$ of $5 \mathrm{~m} \Omega$. A series resistor, $R_{\mathrm{S}}$ of $100 \mathrm{~m} \Omega$ is added in series with the transformer leakage inductance. The resistor $R_{\mathrm{S}}$ represents any resistance that may exist in the transformer winding and connection points of a practical converter.

\section{3P-BIDC Simulation Results}

This section presents the results obtained from the PSCAD simulation modelling of the 3P-BIDC using PSM and BMS with conducting periods of $10 \%, 30 \%$ and $50 \%$. The simulation for Figures 6 to 9 are at their rated conditions.

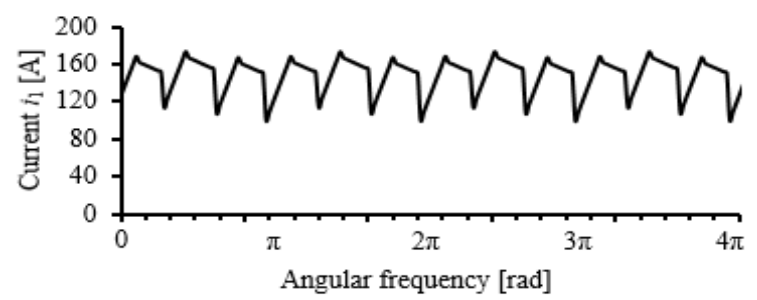

(a)

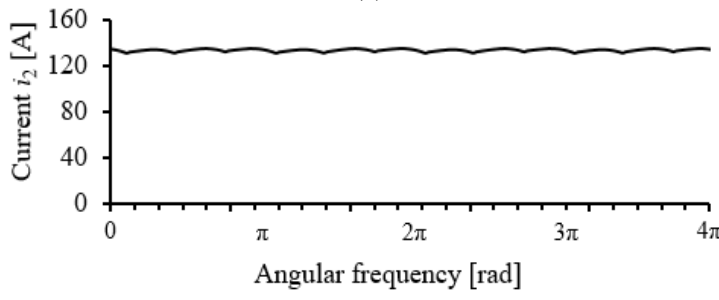

(b)

Fig. 9: DC current waveforms using phase-shift modulation. (a) Bridge 1 and (b) Bridge 2.

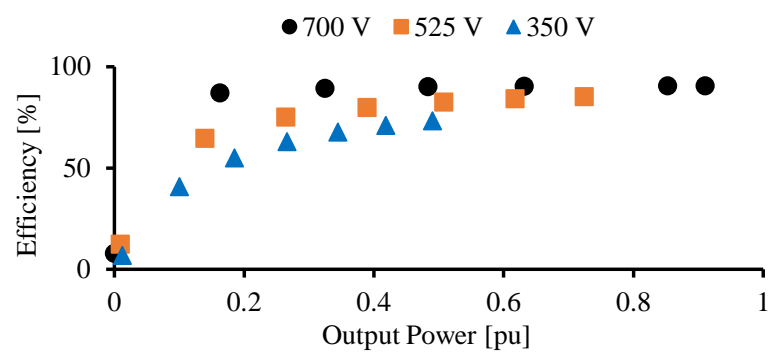

Fig. 10: Efficiency versus output power using PSM for $V_{\mathrm{b}}$ of $700 \mathrm{~V}, 525 \mathrm{~V}$, $350 \mathrm{~V}$ and $V_{1}=700 \mathrm{~V}$.

\subsection{Phase-Shift Modulation}

Figure 6 shows the gate signals for $\mathrm{T}_{11}$ and $\mathrm{T}_{21}$ using PSM. Both gate signals have duty cycles of $50 \%$. The phase-shift angle $\delta$ is varied between $-30^{\circ}$ to $30^{\circ}$. The feasibility of the PSM using different values of $V_{2}$ and $\delta$ are investigated. The power transfer from bridge 2 to bridge 1 that is obtained by setting the phase-shift angles from $-30^{\circ}$ to $0^{\circ}$ are verified to transfer the same range of power when the phase-shift angle is $0^{\circ} \leq \delta \leq 30^{\circ}$ as the design of the converter is symmetrical.

Figure 7 presents the $\mathrm{AC}$ voltage waveform of phase $\mathrm{A}$ of bridges 1 and 2 . The voltage values of $468 \mathrm{~V}$ and $233 \mathrm{~V}$ correspond to $2 / 3 V_{1}$ and $V_{1} / 3$, respectively. The waveforms of bridge 1 leads bridge 2 by $30^{\circ}$ phase-shift at the rated power of $100 \mathrm{~kW}$.

Figure 8 shows the high-frequency AC current waveforms in each phase. The current waveforms are phase-shifted by $120^{\circ}$ with the peak current at $\pm 160 \mathrm{~A}$ at $\delta=30^{\circ}$ and $V_{\mathrm{b}}=700 \mathrm{~V}$. The AC current waveforms are similar to the theoretical $\mathrm{AC}$ current waveforms described in section 2 .

Figure 9 presents the input and output DC current waveforms at $30^{\circ}$ phase-shift angle. The current $i_{1}$ has a ripple of $40 \%$ and the current $i_{2}$ has a ripple of $2 \%$, when the battery is charged from source $V_{1}$ at the rated power. The frequency of the DC current is $40 \mathrm{kHz}$.

Figure 10 presents the efficiency of the 3P-BIDC using PSM for various battery voltage, $V_{\mathrm{b}}$ of $700 \mathrm{~V}, 525 \mathrm{~V}$, and $350 \mathrm{~V}$ accordingly. Note that the rated output power can only be achieved at $\delta>30^{\circ}$ when the magnitudes of $V_{\mathrm{b}}$ is less than $700 \mathrm{~V}$. However, the output current will be increased beyond the converter rated current, which
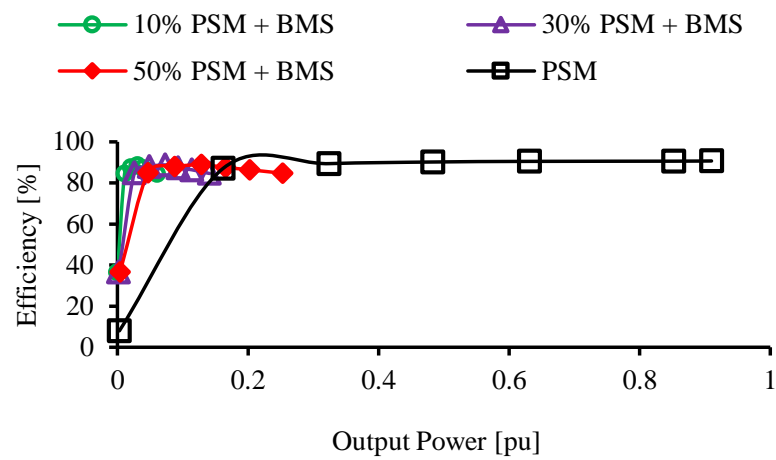

(a)

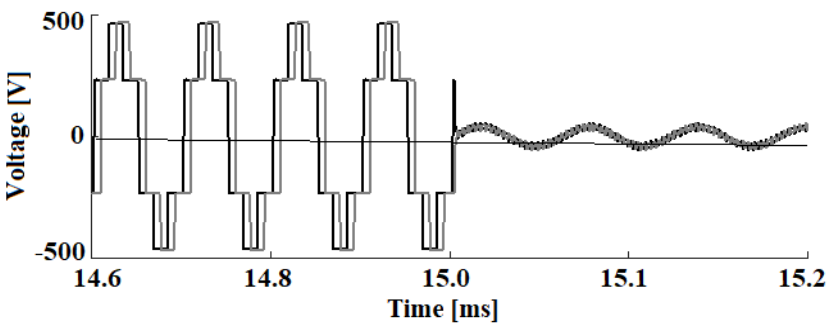

(b)

Fig. 11: AC voltage waveforms of phase A in bridge 1 and 2 (a) Within one cycle of BMS ( $m=30 \%$ ) at $V_{\mathrm{b}}=700 \mathrm{~V}$ (b) Time-expanded waveform of (a).

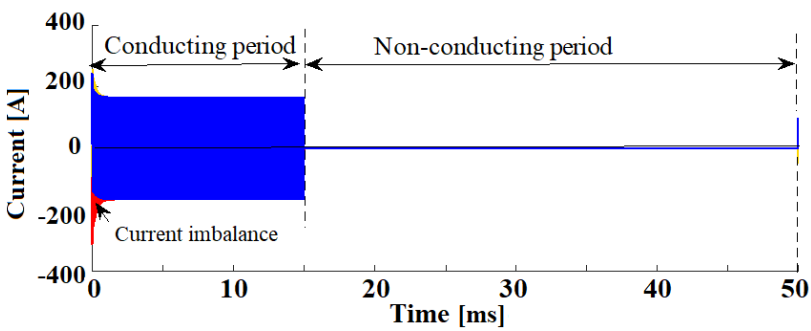

(a)

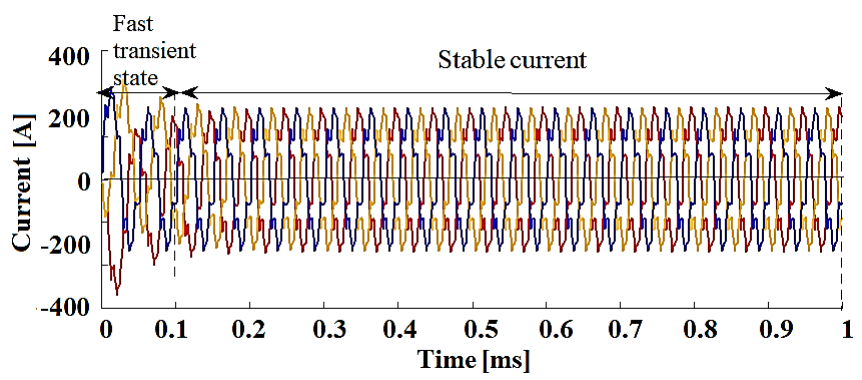

(b)

Fig. 12: Inductor current waveforms at $\delta=30^{\circ}, V_{1}=V_{\mathrm{b}}=700 \mathrm{~V}$. (a) Within one cycle of BMS $(m=30 \%)$ (b) Time-expanded waveform of (a).

is impractical. The maximum output power achieved at $\delta=30^{\circ}$ is when $525 \mathrm{~V}$ and $350 \mathrm{~V}$ is $0.724 \mathrm{pu}$ and 0.490 pu respectively. 


\subsection{Combination of Phase-Shift Modulation and Burst- Mode Switching}

Figure 11 (a) shows the AC voltage waveform when $m$ is set at $30 \%$. The switching occurs for 300 complete cycles and goes through a non-conducting state after $15 \mathrm{~ms}$. Figure 11 (b) shows the last four cycles out of the 300 cycles at the transition from the conducting state to the non-conducting state. It is confirmed that the waveforms are similar to the waveforms obtained in PSM technique except that the cycle is not continuous and oscillates as long as the duration of $m$.

Figure 12 demonstrates the three-phase inductor current waveforms when the low-frequency signal is set to $30 \%$, the inductor current

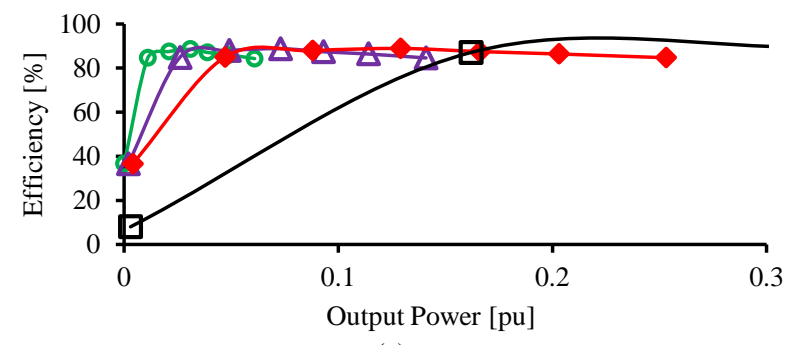

(a)

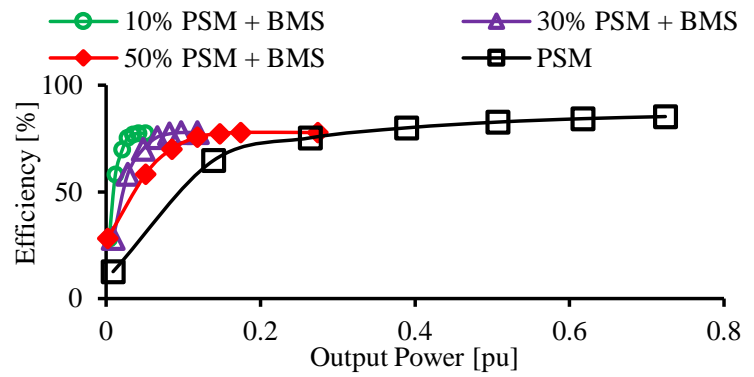

(b)

Fig. 13: Comparison of efficiency versus output power (a) between PSM and BMS $(m=10 \%, m=30 \%$, and $m=50 \%)$ when $V_{\mathrm{b}}=700 \mathrm{~V}$ and $0 \leq \delta \leq 30^{\circ}$ (b) Time-expanded efficiency curve of (a).

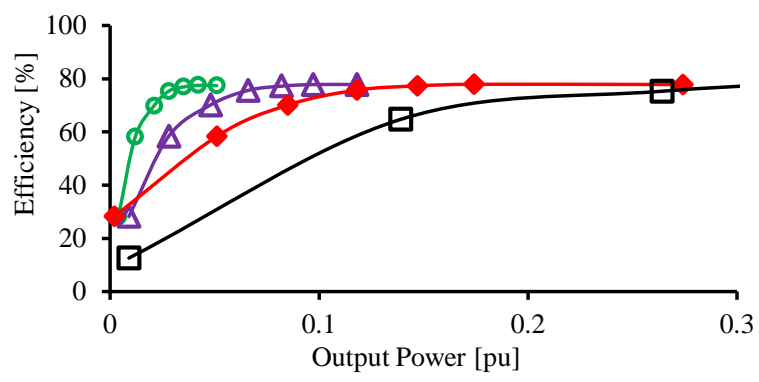

(a)

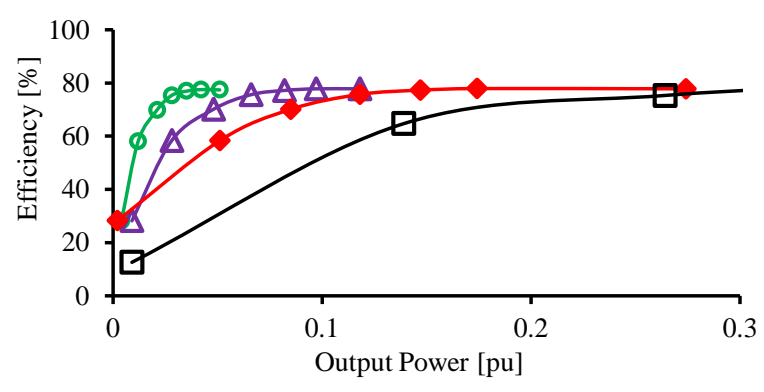

(b)

Fig. 14: Comparison of efficiency versus output power (a) between PSM and BMS ( $m=10 \%, m=30 \%$, and $m=50 \%$ ) when $\mathrm{Vb}=525 \mathrm{~V}$ and $0 \leq \delta \leq 30^{\circ}$ (b) Time-expanded efficiency curve of (a).

flows in the converter for $15 \mathrm{~ms}$. As shown in Figure 12 (b), the setting time for inductor current transient is $0.1 \mathrm{~ms}$.
Figure 13 presents the relation of the converter efficiency with change in output power at $V_{1}=V_{\mathrm{b}}=700 \mathrm{~V}$. It is shown that when BMS with conduction duration of $10 \%, 30 \%$ and $50 \%$ is combined with PSM, the efficiency of the converter is improved significantly. At the output power of $0.1 \mathrm{pu}$, the converter efficiency increases by $27 \%$ when $m=50 \%$. Figure 14 (b) shows the time expanded efficiency curve. As the output power becomes lower, less than 0.028 , different conduction period results in different converter efficiency. At the output power of $0.028 \mathrm{pu}$, it is shown that, when BMS with $m=10 \%$ is applied, the converter efficiency is $88.5 \%$. However, when BMS with $m=50 \%$ is applied, the converter efficiency is $65 \%$.

Figure 14 presents the relation of the converter efficiency with change in output power at $V_{1}=700 \mathrm{~V}$ and $V_{\mathrm{b}}=525 \mathrm{~V}$. It is shown that when BMS with conduction duration of $10 \%, 30 \%$ and $50 \%$ is combined with PSM, the efficiency of the converter is improved significantly when the output power is less than $0.16 \mathrm{pu}$, the converter efficiency is increased by $27 \%$ when $m=30 \%$. Figure 15 (b) shows the time expanded efficiency curve. Similar to Figure 13, there are differences in converter efficiency as a result of varying conduction period. At the output power of $0.028 \mathrm{pu}$, it is shown that, when BMS with $m=10 \%$ is applied, the efficiency is $75.3 \%$. However, when BMS with $m=30 \%$ is applied, the efficiency is $58.3 \%$.

\section{Conclusion}

This paper discusses the design and operation of a three-phase bidirectional isolated dc-dc converter (3P-BIDC). In particular, it presents an enhanced switching strategy that combines phase-shift modulation and burst-mode switching for low-load operation of the 3P-BIDC. The dc-dc converter model and enhanced switching strategy are verified via a simulation. The proposed switching strategy is shown to be effective in improving the dc-dc converter efficiency at low-load conditions with the conduction period $m$ as the main controlling variable and the BMS frequency fixed at $20-\mathrm{Hz}$. It is observed that different conduction period may result in varying the efficiency improvement levels. For future work, the operation and efficiency improvements will be verified via an experimental setup.

\section{Acknowledgement}

The authors would like to thank the Ministry of Higher Education for providing financial support through FRGS Project No. FRGS/1/2017/TK04/UNITEN/02/4.

\section{References}

[1] H. Van Hoek, M. Neubert, and R. W. De Doncker, "Enhanced modulation strategy for a three-phase dual active bridge - Boosting efficiency of an electric vehicle converter," IEEE Trans. Power Electron., vol. 28, no. 12, pp. 5499-5507, 2013.

[2] N. M. L. Tan, T. Abe, and H. Akagi, "Design and performance of a bidirectional isolated DC-DC converter for a battery energy storage system," IEEE Trans. Power Electron., vol. 27, no. 3, pp. $1237-$ $1248,2012$.

[3] X. She, X. Yu, F. Wang, and A. Q. Huang, "Design and demonstration of a 3.6-kV-120-V/10-kVA solid-state transformer for smart grid application," IEEE Trans. Power Electron., vol. 29, no. 8, pp. 3982-3996, 2014

[4] J. R. Rodriguez-Rodriguez, E. L. Moreno-Goytia, V. VenegasRebollar, L. E. Ugalde-Caballero, and G. A. Anaya-Ruiz, "The Proportional-Values Modulation (PVM), a technique for improving efficiency and power density of bidirectional DAB converters," Electr. Power Syst. Res., vol. 144, pp. 280-289, Mar. 2017.

[5] H. Bai and C. Mi, "Eliminate reactive power and increase system efficiency of isolated bidirectional dual-active-bridge dc-dc converters using novel dual-phase-shift control," IEEE Trans. Power Electron., vol. 23, no. 6, pp. 2905-2914, 2008. 
[6] R. A. Abramson, S. J. Gunter, D. M. Otten, K. K. Afridi, and D. J Perreault, "Design and evaluation of a reconfigurable stacked active bridge dc/dc converter for efficient wide load-range operation," Conf. Proc. - IEEE Appl. Power Electron. Conf. Expo. - APEC, no. 1307699, pp. 3391-3401, 2017.

[7] G.-J. Su and L. T. L. Tang, "A Three-Phase Bidirectional DC-DC Converter for Automotive Applications," 2008 IEEE Ind. Appl. Soc Апnи. Meet., pp. 1-7, 2008

[8] E. De Din, H. A. B. Siddique, M. Cupelli, A. Monti, and R. W. De Doncker, "Voltage Control of Parallel-Connected Dual-Active Bridge Converters for Shipboard Applications," IEEE J. Emerg. Sel. Top. Power Electron., vol. 6, no. 2, pp. 664-673, 2018.

[9] H. Choi, J. Lee, Y. P. Cho, and J. H. Jung, "Design consideration of efficinecy improvement in three phase dual active bridge converter for LVDC application," INTELEC, Int. Telecommun. Energy Conf., vol. 2017-Octob, pp. 549-555, 2017.

[10] N. H. Baars et al., "A 80-kW Isolated DC - DC Converter for Railway Applications," vol. 30, no. 12, pp. 6639-6647, 2015.

[11] R. W. A. A. De Doncker, D. M. Divan, and M. H. Kheraluwala, "A Three-Phase Soft-Switched High-Power-Density DC/DC Converter for High-Power Applications," IEEE Trans. Ind. Appl., vol. 27 , no. 1 , pp. 63-73, 1991

[12] Z. Xuan, H. Shenghua, and N. Guoyun, "A Three-phase Dual Active Bridge Bidirectional ZVS DC/DC Converter," Phys. Procedia, vol. 24, pp. 139-148, 2012.

[13] Z. Li, Y. Wang, L. Shi, J. Huang, and W. Lei, "Optimized modulation strategy for three-phase dual-active-bridge DC-DC converters to minimize RMS inductor current in the whole load range," 2016 IEEE 8th Int. Power Electron. Motion Control Conf. IPEMC-ECCE Asia 2016, pp. 2787-2791, 2016.

[14] H. Zhou and A. M. Khambadkone, "Hybrid modulation for dualactive-bridge bidirectional converter with extended power range for ultracapacitor application," IEEE Trans. Ind. Appl., vol. 45, no. 4, pp. 1434-1442, 2009

[15] Y. M. Hirofumi Hisamochi, Hirofumi Akagi, Shin-ichi Kinouchi, "Enhancement of Power Conversion Efficiency in a Low-Power Range of a Bidirectional Isolated DC-DC Converter by Intermitten Operation," IEEJ Trans. Ind. Appl., vol. 136, pp. 501-508, 2016.

[16] G. G. Oggier and M. Ordonez, "High-efficiency DAB converter using switching sequences and burst mode," IEEE Trans. Power Electron., vol. 31, no. 3, pp. 2069-2082, 2016.

[17] F. Reverter and M. Gasulla, "Optimal Inductor Current in Boos DC/DC Converters Operating in Burst Mode Under Light-Load Conditions," IEEE Trans. Power Electron., vol. 31, no. 1, pp. 1520, 2016.

[18] Z. Chen, W. Xinke, and Q. Zhaoming, "Design and comparison of two front-end Dc/Dc converters: LLC resonant converter and softswitched phase-shifted full-bridge converter with primary-side energy storage inductor," Conf. Proc. - IEEE Appl. Power Electron. Conf. Expo. - APEC, pp. 1073-1077, 2009.

[19] Y. Cui, D. Wang, and A. Emadi, "Three-Phase Dual Active Bridge Converter Design Considerations,” pp. 4696-4701, 2017.

[20] R. O. Núñez, G. G. Oggier, F. Botterón, and G. O. García, "A comparative study of Three-Phase Dual Active Bridge Converters for renewable energy applications," Sustain. Energy Technol. Assessments, vol. 23, pp. 1-10, 2017.

[21] Z. Y. Tan, N. M. L. Tan, and I. S. Hussain, "Theoretical Analysis of a Three-Phase Bidirectional Isolated DC-DC Converter Using Phase-Shifted Modulation," Int. J. Power Electron. Drive Syst., vol. 9, no. 2, pp. 495-503, 2018 